\title{
Can Girls Attend and Complete School in Ghana; Measuring Parents Educational Status as a Factor of Confidence and Belief in Girls Education
}

\author{
Emmanuel Wedam $^{1, *}$, Job Asante ${ }^{2}$, Irene Akobour Debrah ${ }^{3}$ \\ ${ }^{1}$ Department of Development Studies, University for Development Studies, Wa, Ghana \\ ${ }^{2}$ School of Business and Law, University for Development Studies, Wa, Ghana \\ ${ }^{3}$ Faculty of Education, University for Development Studies, Wa, Ghana \\ *Corresponding author: emmanuel.wedam@yahoo.com
}

Received May 13, 2014; Revised June 19, 2014; Accepted July 03, 2014

\begin{abstract}
Available statistics indicates that girls are disproportionately at a disadvantage in the acquisition of formal education in Ghana. Attempts to balance this have over the years focused mainly on dealing with socioeconomic and cultural factors without recourse to other visible yet covert factors that affect parents' attitude towards formal education. This study examines whether parents educational status has any influence, effect and impact on their belief and confidence about whether girls can attend, excel and complete school in Ghana. A mixed method approach was adopted for the study. There were significant differences in the response variables. Parents who had never attended school before had a very high belief bias about the ability of girls to attend, excel and complete school than parents who had ever attended school before. About 26.5 percent of parents did not have confidence and belief girls can attend, excel and complete school in Ghana as against 73.5 percent of patients who shared a different opinion. In this study, we are convinced that even though stakeholders are continuously working to remove the barriers in girls' acquisition, completion and transition in school, focus must generally be directed to the parental factors. The study concludes that if any concrete results can be achieved in the fight to create gender parity then the factors that influence parents' perception about girls education must be critical addressed.
\end{abstract}

Keywords: girls, parents, formal education, belief and confidence, educational status

Cite This Article: Emmanuel Wedam, Job Asante, and Irene Akobour Debrah, "Can Girls Attend and Complete School in Ghana; Measuring Parents Educational Status as a Factor of Confidence and Belief in Girls Education." American Journal of Educational Research, vol. 2, no. 7 (2014): 493-502. doi: 10.12691/education-2-7-11.

\section{Introduction}

Formal education is a fundamental human right for all. As a consequence, over the years, there have been serious efforts at promoting the acquisition of formal education in the world. The main idea behind this initiative is potted on the fact that "formal education provides opportunity for social mobility and escape from poverty” [[5], p.42].This is particularly significant among girls, who have traditionally often been exposed and are usually crowded out and fall to the precincts of today's complex and competitive environment. Prescriptions from the international community and national governments have emphasized investments in formal education for girls. According to the United Nations Children's Fund, “investing in girls' education today is a strategy that will protect the rights of all children to quality education.....and a strategy that will jump-start all other development goals” [[18], p.ii]. Even though the adaption of the 1948 Universal Declaration of Human Rights, the 1995 Beijing Conference and other major international conventions and protocols brought on top of the international development memo about the respect for the fundamental Human Rights for all. It was the 1990 World Conference on Education for All (EFA) held in Jomtien, the Convention on the Rights of the Child, the World Education Forum 2000, in Dakar and the 2000 Millennium Development Goals (MDGs) that traditionally and significantly inserted the urgent need to accelerate girls' acquisition of formal education.

However, over several decades of investments and efforts by the international and donor community as well as national governments to make formal education accessible, acceptable and affordable to girls', the intricacies of providing quality, inclusive and equitable education for all girls in Africa still remains a major headache.

In Ghana, a number of factors have stymied the ability of girls to attend, excel and complete school. Girls in Ghana are "less likely to attend school regularly than boys and if and when they attend class, they are less likely to concentrate and ask/answer questions because of the amount of house chores they are forced into undertaking. A girl may be asked to stay home to take care of a sick person/younger sibling, fetch water among other domestic responsibility" [[1], p.1]. Other environmental factors 
such as psychological, physical and sexual harassment on girls also tend to exacerbate the already fragile low participation of girls in formal education thus making girls less visible in class and in school [Ibid]. There are also a wide range of factors such as violence, religion, culture and personal belief systems which encumber girls' concentration in class, school attendance, completion of homework and partaking in classroom work, which are really related to girls' educational participation [Ibid].

Today, the trajectory of the problem is well known among development actors, governments and civil society organizations in Ghana. Recommendations and interventions from these institutions and organizations and local actors have over the years focused on awareness creation, increase funding, counseling, law enforcement, the introduction of conditionality for financial baits inter alia. Again, significant evidence abound that the trajectory of this phenomenon is very pronounced in most rural communities in the country particularly in the Northern Region of the country.

Over the years, the government of Ghana has made serious strives to improve education at all levels. For instance, the government is committed to ensure that it achieves Universal Primary Education for All by 2015 as encapsulated in the UN Development Goals (MDG 2) [17]. This commitment is captured in various reports and policy frameworks of government such as the 1992 constitution, the Free Compulsory Universal Basic Education (FCUBE) policy, Education Strategy Plan (ESP) for 2003- 2015 and the Ghana Poverty Reduction Strategy [Ibid]. Other direct interventions such as the introduction of the capitations grant, school feeding, the establishment of girls educational units within the Ministry of Education and other programmes introduced in underserved communities to motivate teachers and girls such as pay increase for rural teachers, the distribution of free exercise books, uniforms, and bicycles for girls are all attempts aimed at achieving gender parity in girls' education.

However, today, there is still clear evidence that the levels of school attendance, school retention, school completion and educational transition among girls in Ghana within the various echelons of the educational structures are progressively worsening. For instance, girls' school enrolment declines significantly from 0.97 of General Performance Index (GPI) at the primary school level to below 0.6 of GPI at the tertiary level [1]. The cumulative effect has been the poor and low representation of the concerns and issues of girls as well as women's participation in politics and social and economic engagements of the country. This is against the background that about 51 percent of the population in the country is made up of women [Ibid]. In some cases, women's involvement in community participation and development projects has been withdrawn [20].

On the global scale, it is estimated that there are about 69 million children who are out of school, out of this number 54 percent are girls [1]. "Once in school, girls are faced with numerous challenges and are more likely than boys to stop attending before they complete primary education. Girls also have significantly less chances of progressing to secondary school in many parts of the world including Ghana. Of the 759 million adults lacking literacy skills, two-thirds are women - a share that has actually increased slightly over the last decade. Poor and marginalised women and girls are disproportionately affected, with factors such as; ethnicity, disability and location dramatically worsening a girl's chance of entering and completing school. These facts highlight a scandalous denial of human rights" [Ibid, p.1].

According to the Ghana Statistical Service [5], educational enrolment among girls in both primary and junior high school is the Northern region is far lower than their male counterparts. The point is that, girls in the region are usually locked up in "a vicious cycle in which their struggle to get an education instead of being married in an early age expose them to violence and abuse, which then leads to low level of academic performance, class repetition and eventually dropping out of school” [[1] p.1]. In effect, "because of the complexities in the acquisition of formal education, most girls in the Northern Region tend to compliment formal education with informal job apprenticeship such as trading. The essence of doing this is to create a safety net for themselves when schooling fails” [[18] p.166]. This is a clear sign of trepidation that they might not make it through formal education.

Even though a number of stakeholders, policies and legislations have significantly encapsulated the capacity and potentials of girls to excel in formal education, the reality of the problem is that, even among and within stakeholders themselves there are piebald views about whether girls can attend, excel and complete school. The trajectory of these views is well mapped in rural and local communities everywhere in the world.

Again, even though enrolment levels and school attendance ratio among girls is increasing in some areas in the Northern region not many girls who attend school are able to excel or complete successfully. This is due to a horde of factors such as family size, household chores, funding and school factors inter alia. However, one critical factor whose impact, effect and influence is not clearly known is the educational status of parents.

To suffice, the significance of this study is lugged on the fact that despite several years of intervention by stakeholders cultural, religious and personal belief systems as well as a host of environmental factors at home and at school, there are still major tailbacks to girls' completion of formal education and the effort of stakeholders in achieving gender parity. Among these factors, what is particularly disquieting and yet covert is the educational status of parents. This research therefore seeks to examine whether there are any significant differences in parents' educational status and the belief as well as confidence that parents have about the ability of girls to attend, excel and complete school.

\section{Theory}

\subsection{Belief Bias Model}

Belief is been a significant part of human existence. It is a psychological condition where a person or people hold or embrace an assumption or an idea to be true. This study utilised the belief bias model. The belief bias model postulates that individuals or people without any opposition or careful consideration of what really and actually they are concerting tend to belief things and issues that fit into their scheme or belief system. On the 
other hand, albeit some idea or claim is feasible, true or logical, people will snub, discard or throw it out once it does not fit into their belief systems $[8,10]$.

The belief bias model holds perfectly under situations and circumstances in which people will usually neglect and disregard the premise and concentrate on the final analysis or conclusion. People tend to reason and belief base on their exposure and experience on issues rather than by logic or what is true. It is significant to stress the point that, under the belief bias model, any attempt to change people's belief and views outside their already established belief system will fail since it does not fit in. The reverse is also true $[4,5]$.

\section{Conceptual Framework}

Governments and other stakeholders have been making immense contributions to the promotion of formal education because it is a fundamental right to all as espoused in the Universal Declaration of Human Rights, 1948. The acquisition of formal education is believed will significantly enhance people's knowledge and skills [9]. In this study, it is postulated that parents who have attended school before will be influenced by their educational status to break cultural, religious and personal belief systems. Thus, we postulated that parents who have ever attended school have a positive belief (positive belief bias) and confidence in the ability of girls to attend and complete school. This is because of their exposure and experience on issues regarding education.

In the same vein, we postulated that parents who have never attended school before are influenced by their educational status. We belief that, the educational status of parents who have never attended school before has a negative influence on their belief and confidence in respect of the ability of girls to attend, complete or excel in schooling. This is also due to the exposure and experience of these people in education.

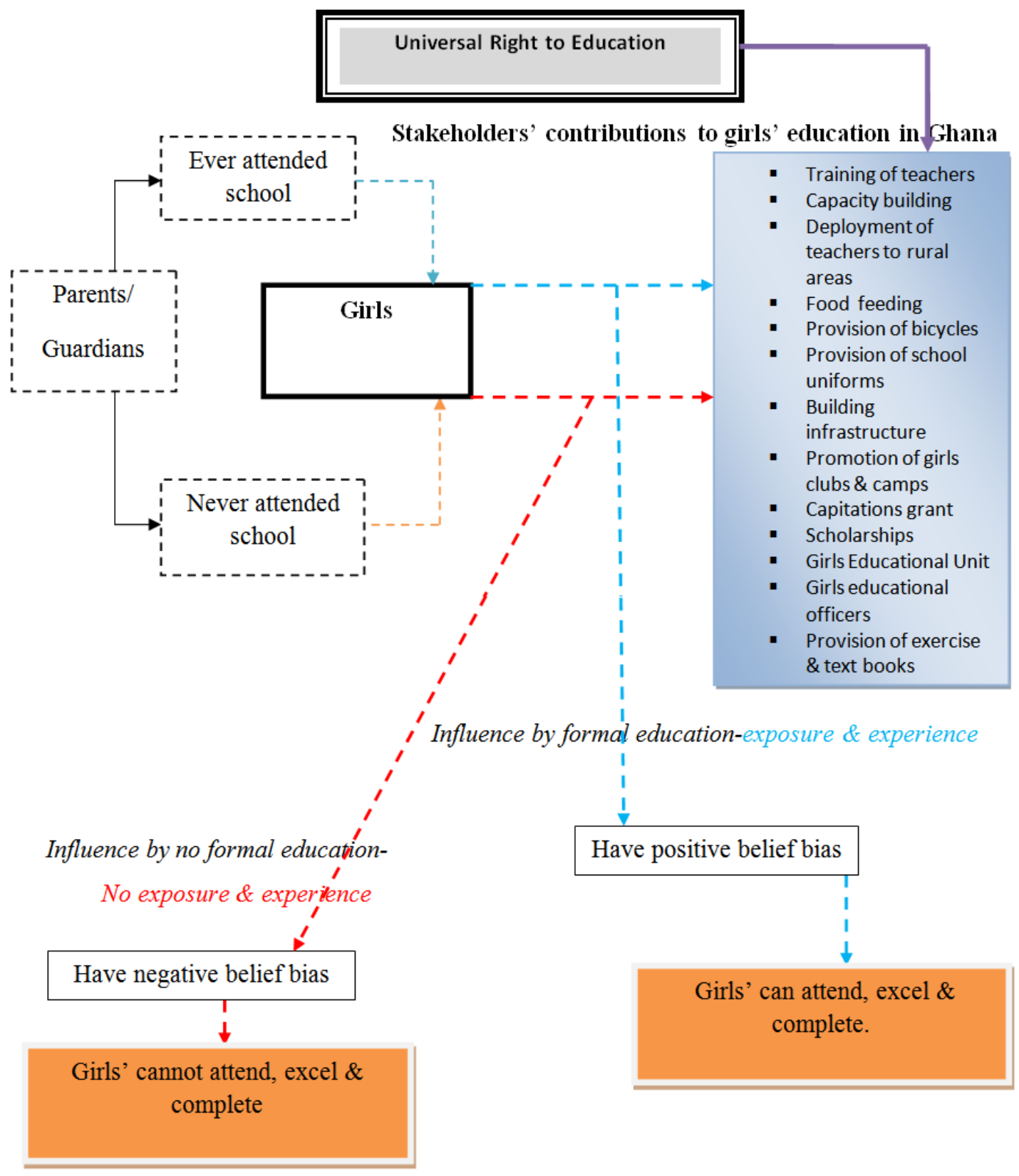

Source: Authors Own Construct, 2014.

Figure 1. Conceptual framework for analysing parents' belief and confidence in the ability of girls to attend, excel and complete school in Ghana 
In this study, we assumed that parents who have ever attended school before and parents who have never attended school before can all be influenced by belief bias but it is parents who have never attended school before that have a very high degree of belief bias and low confidence. In our view, we belief that even though some idea may be feasible, true or logical it is parents who have never attended school before that will snub, discard or throw it out once it does not fit into their belief systems $[10,13]$. Base on the research problem and the theoretical model (belief bias) we have formulated a conceptual frame work to help us analyse parents' belief and confidence in the ability of girls to attend and complete school. The Figure 1 presented below shows the conceptual framework of the study.

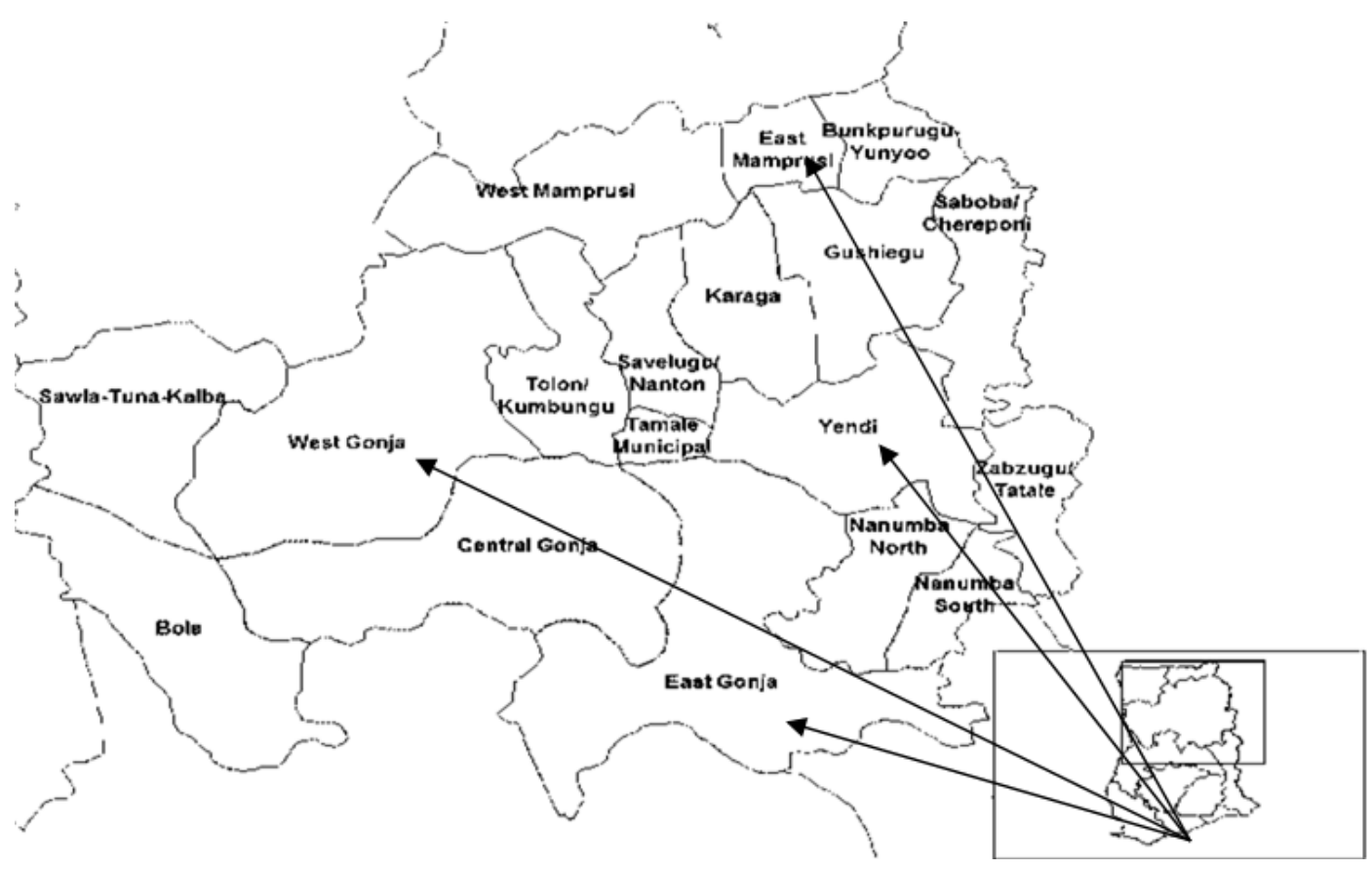

Figure 2. Map showing the Study Area (Source: Districts in Ghana, 2014)

\section{Methodology}

\subsection{Study Area}

The study areas are in the Northern region of Ghana which covers an area of 70,384 $\mathrm{km}^{2}$. In the 2000 Population and Housing Census, the population of the region stood at $1,820,806$ [6]. According to the Ghana Statistical Service [Ibid] formal educational acquisition in the study areas is very low. The percentage of people 15 years and above who are literate is 22.0 percent with the proportion of girls being 12 percent lower than that of boys [Ibid]. Religious distribution in the area is skewed in favour of Islam with about 1,486,937 people being Muslims and about 395,756 people practicing Traditional African Religion. The Figure 2 presented below shows the study areas of the research.

\subsection{Research Design}

In this paper, we adopted a case study design [2,15,23]. According to Stakes, case studies are a strategy of research where the researcher tries to explore in detail and thoroughly a process, event, programme, activity, or better still one or a number of individuals [15]. "Cases are bounded by time and activity, and researchers collect detailed information using variety of data collection procedures over a sustained period of time” [[3], p.3 as cited in 15].

Again, in order to broaden the understanding of the research problem we decided to employ a mixed method strategy. According to Creswell [3] "mixed methods procedures employ aspects of both quantitative methods and qualitative procedures. The importance of doing this is to broaden understanding by incorporating both qualitative both qualitative research, or to use one approach to better understand, explain, or build on the results from the other approach” [p.205].

\subsection{Data Collection Procedures and Analysis}

To begin with, the researchers first considered the total number of districts in the Northern region of Ghana. After an initial survey of 20 districts in the region, we decided to select four (4) districts for the study. The decision to select four districts was based on the fact that in qualitative research the main concern is to select sites that will help the researcher understand the research problem [Ibid]. More to the point, during the initial survey, it was realised that all the districts in the region had similar educational features. This makes the population a homogenous one.

After this, a number of specific steps were undertaken in other to select the actual four districts for the study. In doing this, we employed simple random sampling focusing mainly on the lottery method. The decision to do this was because we realised that the study population was a homogenous one. Simple random sampling is a basic probability sampling technique commonly used in social research and is widely used by most social researchers. According to Moore and McCabe [11] simple random sampling of $\mathbf{n}$ containing $\mathbf{n}$ respondents from the universe must be selected in such a manner that every $\mathbf{n}$ respondent has a random or equal opportunity of being the sample selected. 
Before we could obtain the actual four districts for the study, all the districts in the region were numbered on separate sheets of paper. These sheets were of the same shape, colour and size. The sheets of paper were folded and kept in a container and welled mixed. After this, one of the researchers was blindfolded and made to select four districts from the container. The districts selected from the container were West Gonja, East Gonja, Yendi and East Mamprusi district. By doing this, we ensured that the selection of the four districts was done by chance or randomly.

After the selection of the districts, the researchers were confronted with the task of deciding on the actual number of respondents that will be involved in the study. Since it was difficult to estimate the total population of the study, the researcher decided to use a sample of two hundred (200) respondents. According to Creswell [3] in qualitative studies, the selection of respondents' does not necessary requires the selection of a large number of participants as typically found in quantitative research. The sample selection of respondents is presented in Table 1 below.

Table 1. Sample of Respondents

\begin{tabular}{|c|c|c|}
\hline Educational Status & Districts & $\begin{array}{c}\text { Selection of } \\
\text { Respondents }\end{array}$ \\
\hline Educated and Non Educated & Yendi & 50 \\
\hline Educated and Non Educated & West Gonja & 50 \\
\hline Educated and Non Educated & East Mamprusi & 50 \\
\hline Educated and Non Educated & East Gonja & 50 \\
\hline Educated and Non Educated & Total & $\begin{array}{c}\text { Educated-100, Non } \\
\text { Educated-100 = 200 }\end{array}$ \\
\hline $\begin{array}{l}\text { Total Number of Males }=100, \text { Total Number of Females 100, Total No } \\
\text { of respondents = 200 }\end{array}$ \\
\hline
\end{tabular}

In conducting this research, the researchers decided to select educated and non educated people. This was because we did not only wanted to find out about peoples belief and confidence about whether girls can attend and complete school in Ghana but we actually wanted to find out or see the differences within these two groups and how the response variables vary and the extent to which they vary from each other depending on their distinct characteristics.

In order to improve on the quality of data collection we employed triangulation $[7,8,14]$ in the data collection process. This procedure by prescription required that data is assembled from an assortment of sources and techniques. The reason for using "triangulation" was based on the fact that the various sources and techniques could make the final analysis much more credible than if the study were confined to only one source or routine of data collection [Fielding and Fielding, 1986 as cited in 8]. For this reason, we collected data using questionnaires, face-to-face key informant interviews and Focus Group Discussions (FGDs). Again, extensive review of literature from secondary sources such as reports, books and journals was also carried out.

The composition of the FGDs was made up of both males and females. In all, we organised four (4) separate FGDs, with each FGD held in each district (West Gonja, East Gonja, Yendi and East Mamprusi). The number of people or participants in each FGD ranged from nine (9) to eleven (11). According to Tsiboe [16], this technique of data collection is suitable if the objective of the research is to examine the experiences and opinions of a section of the population in relation to some specific issues connected to their environment. Separate FGDs were held each with parents who had ever attended school and parents who had never attended school before. The participants in the FGDs were selected through purposive sampling. According to Creswell [3], the main principle in qualitative research is that the respondents must be selected purposefully and in a manner that will best help the researcher understand the problem under investigation.

In addition, we conducted key informant in-depth face to face interviews in order to enable us capture ancillary information relevant to the study and to also ascertain the precision of the secondary materials that were used in this study. Note taking and audio recording took place during the in-depth face to face interview as well as the FGDs. According to Walliman [19] audio recording during interviews is critical because they preserve and maintain a complete and an un-interrupted recording of what has been said and as a tool to test out against researcher's bias. The respondents who were involved in the in-depth interview were purposively sampled and included teachers, officials from the Ministry of Education, community opinion leaders and representatives from NonGovernmental Organisations (NGOs).

We collected data from both rural and urban communities. Both primary and secondary data were collected from 2013 to 2014. In terms of data analysis, the Statistical Package for Social Scientist (SPSS) and Nvivo were used.

\subsection{Ethical Issues}

The audio recording during the in-depth face to face interviews and FGDs were done with the consent of the respondents who were involved. Again, the in-depth face to face interviews and FGDs were held at the respondents own scheduled time and at their will.

\subsection{Theoretical Model and Analysis}

In conducting this study, a across tabulation and a ChiSquared Test of Independence was performed to measure two independent and dependent variables. The objective was to determine whether there were any significant differences between the educational status of parents as against their belief and confidence in the ability of girl to attend and complete school. The equation for computing the Chi-Square value is given as;

$$
x^{2}=\sum\left[\frac{\left(f_{o}-f_{e}\right)^{2}}{f_{e}}\right]
$$

\section{Where}

$\sum=$ Sum across all categories of the variable

$f_{o}=$ observed frequency

$f_{e}=$ expected frequency

$$
x^{2}=\sum\left[\frac{(\text { observed }- \text { expected })^{2}}{\text { expected }}\right]
$$

\subsection{Hypothesis}


$\boldsymbol{H}_{\mathbf{0}}=$ There is/are no significant differences or relationships between parents educational status and their belief and confidence on whether girls can attend, excel and complete school.

$\boldsymbol{H}_{\mathbf{1}}=\mathrm{H}_{0}$ is not true (two-tail)

Where;

$\boldsymbol{H}_{0}$ refers to the null hypothesis and

$\boldsymbol{H}_{1}$ refers to the alternative hypothesis

In this study, we used a significant value ( $\alpha$-alpha) of 0.05 to test the significance of the results generated from the chi-square. Therefore;

If the $\mathrm{p}$ value of the chi-square is less than five (5) then we reject the null hypothesis. That is, if $\mathrm{p}<0.05$ then we reject the null hypothesis, and accept the alternate hypothesis (There are no differences). On the other hand, if the $p$ value of the chi-square is greater than five (5) then we fail to reject the null hypothesis. That is, if $\mathrm{p}>0.05$ then we fail to reject the null hypothesis.

In this study, $d f$ is referred to as the "degree of freedom" and is defined as $\mathrm{N}-1$, that is the number of items in the group minus one (1) restriction [12].

\subsection{Test of Validity}

The results show that 0 cells $(.0 \%)$ have expected counts less than five (5). This means that we have not violated the minimum expected cell frequency of five (5) which will make our chi-square test inaccurate (see Table 2).

Furthermore, the Continuity Correction significance value (.000) and the Fisher's Exact Test significance value (.000) are all less than the significant value $(\propto)$ of 0.05 . This makes our chi-square test of independence analysis accurate since the p-value of the results obtained is also less than the significant value of 0.05 (see Table 2).

\section{Results and Discussions}

The study revealed that about 87 percent of the respondents, who had ever attended school before had belief that girls can attend and complete school. However, about 74 percent lower, representing 13 percent of the respondents held a contrary view. Within the sampled population of the respondents who had never been to school before, 40 percent of them did not share the view that girls could attend, excel and complete school. In general, the number of people within the different educational status groups who had belief that girls can attend, complete or excel in schooling was more than those who said no. The bar graph (Figure 3) below shows the actual educational distribution and responses of the respondents (Parents) in the study.

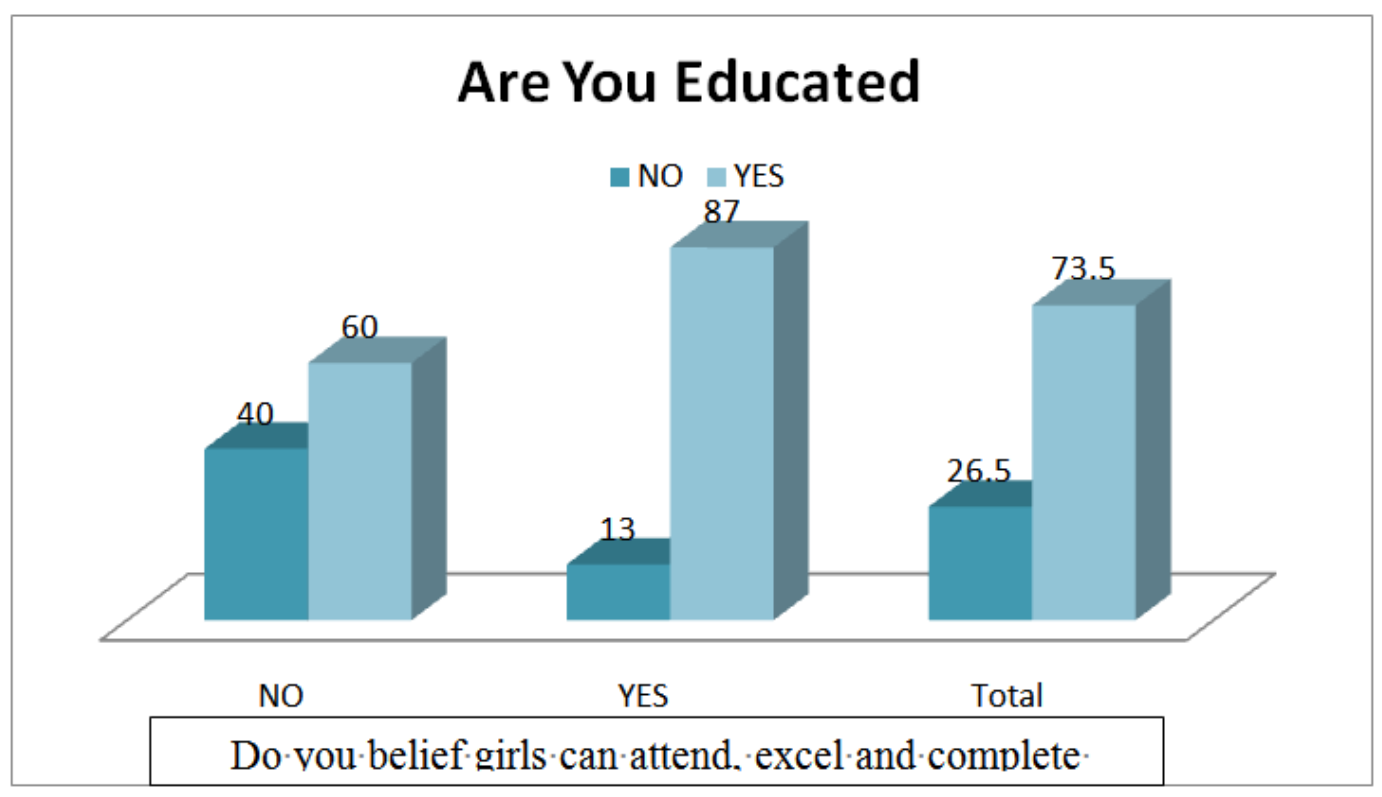

Figure 3. Bar graph showing the educational distribution of respondents (Parents) and their views about girls' ability to attend and complete school (Source: Field Survey, 2014)

The disparities within respondents who had ever attended school before was higher than the respondents who had never attended school before. Some of the factors that accounted for these disparities were the level of exposure and experience of some of the respondents. This is a typical element of the belief bias theory [4,5]. For instance, respondents who had ever travelled outside their communities were quite conceived that girls could attend, excel and complete school. Culture, religious myths and personal beliefs had little influence on the choice of the respondents who had ever attended school before.

Even though majority of the respondents who had ever attended school before (71\%) had belief and confidence that girls can attend, excel and complete school, a significant number that is about 29 percent did not support this view. According to Wedam, Debrah and Quansah [21] and the World Bank [22] parents who have ever attended school in Ghana are more likely to belief that girls can succeed in formal education and hence will take their girls to school. Majority of these respondents were women who dropped out of school as a result of pecuniary and environmental factors. Among the 71 percent of respondents who had belief that girls can attend and complete school, about one-third argued that even though girls had the capacity to attend, excel and complete school, they still required support from the house, school and from government. The pie chart below (Figure 4) shows 
the distribution of views of respondents who had ever attended school before.

\section{Do you have confidence and belief in your girl child to attend and complete school}

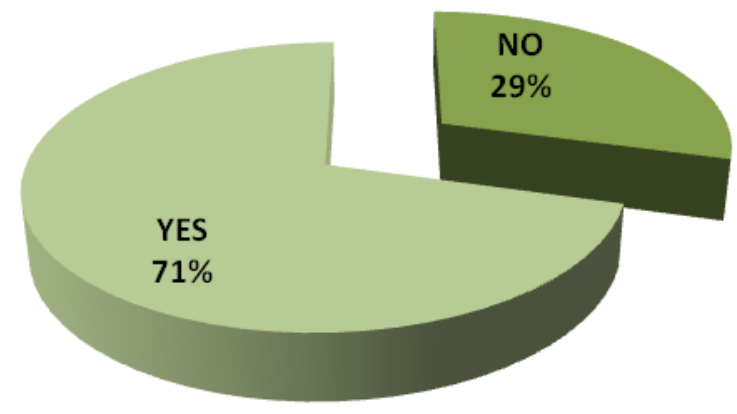

Figure 4. Pie chart showing the distribution of views of respondents who had ever attended school before (Parents) (Source: Field Survey, 2014)

The difference in views among the respondents who had never attended school before was low. That is, within the sampled population of respondents who had not attended school before, less than half of the population representing about 35 percent of them had belief that girls can attend and complete or excel in schooling. During the FGDs it was revealed that even though these respondents had never attended school before, their views were generally influenced by educational campaigns and advertisements on radio and television. Government officials from the Ministry of Education, Non-
Governmental Organisations (NGOs), Faith-Based Organisations have also played a major role in constructing the belief and confidence that these respondents (35\%) espoused. Other factors included the attitude of educated women in the communities. For instance, female community health nurses and teachers were found to have had a very strong influence on the decision of these respondents [21]. The figure (Figure 5) below shows the distribution of views of respondents who had never attended school before.

\section{Do you have confidence and belief in your girl child to attend and complete school}

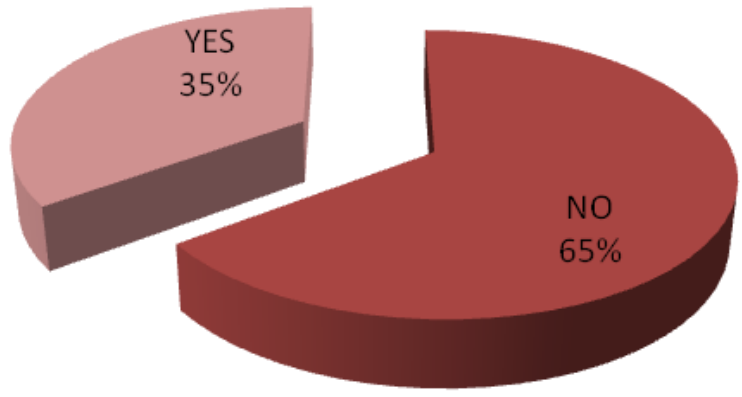

Figure 5. Pie chart showing the distribution of views of respondents who had never attended school before (Parents) (Source: Field Survey, 2014)

Religious and cultural factors were found to be very strong forces that bigoted the belief and confidence of about 70 percent of the respondents who had never attended school before. These respondents had developed a belief bias attitude towards girls' education based on their religion, culture and personal belief systems. The study revealed that religion, culture and personal belief systems had provided an emplacement where the level and rate of girls' acquisition of formal education in the Northern region of Ghana is vexed.

Among the respondents who had never attended school before poverty, teacher's attitude, household chores, farm labour requirements, family size, peer pressure, pregnancy, and lack of confidence, single parenting, low motivation, 
early marriage, low level of concentration and child promiscuity were found to be the factors that influenced their views. Among these factors, early marriage, teenage pregnancy, child promiscuity and low concentration were the major driving factors that influenced the views of these respondents.

Even though there were evidences of improved infrastructure, increased funding, food rationing for retention, capacity building, and provision of free exercise books, uniforms and bicycles for girls inter alia, these improvements did not have any influence on the respondents who had never attended school before. This was because over a period of time, a high belief bias syndrome and low confidence had developed among the respondents thus evaporating the significant contributions and interventions by stakeholders. To suffice, culture, religion, personal beliefs and evidences of high school dropout among girls have conspired to cement a very high belief bias syndrome and low confidence among the respondents who have never attended school before. These findings confirm the findings of Wedam, Debrah and Quansah [21] that parents who have never ever attended school in Ghana are less likely to belief or have confidence in the ability of their girls to attend and complete school and will there not take their girls to school.

\subsection{The Gender Perspective}

In this study, we have tried as much as possible to explore the differences in perspectives and belief regarding the ability of girls to attend, excel and complete school in Ghana. In as much as there were wide disparities in the responses of parents who had ever attended school and parents who had never attended school before, the differences in gender also show wide disparities between males and females. The Figure 6 below shows the various responses from the various gender groups.

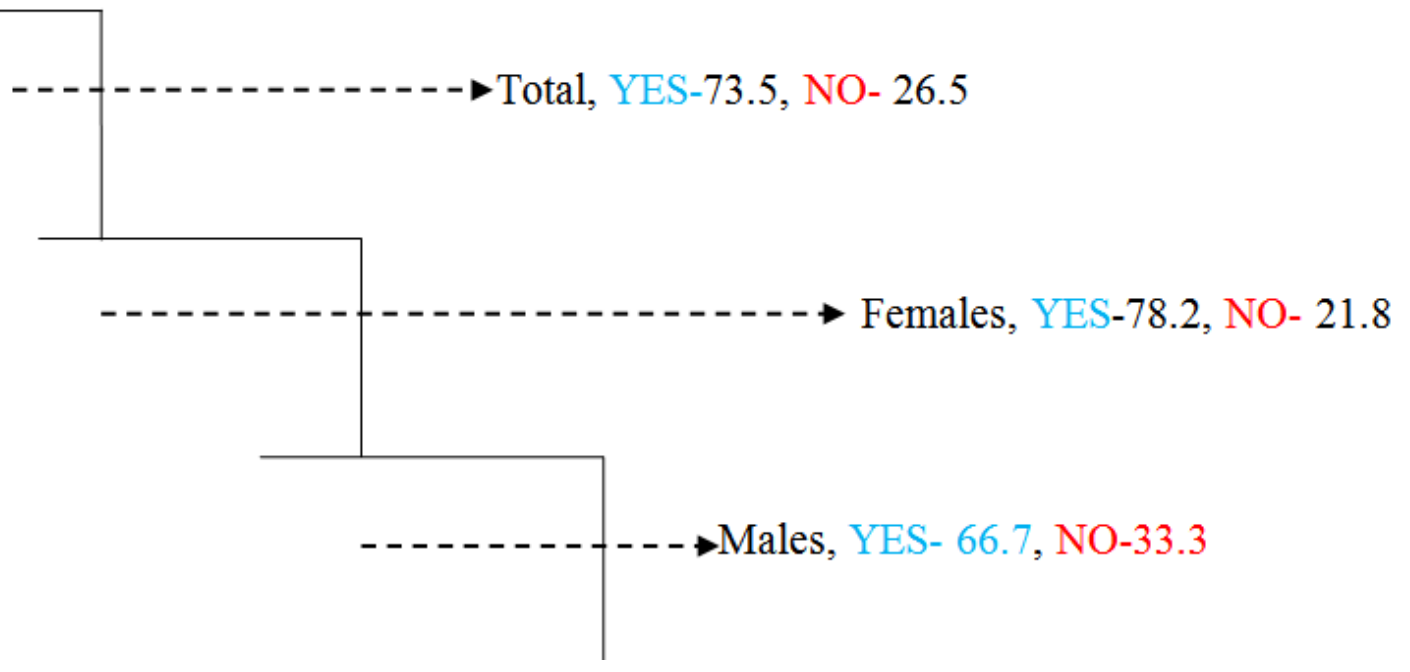

Figure 6. Figure showing the disparities in gender views (Source: Field Survey 2013-2014)

Even though more females (78.2) than males (66.7) had belief that girls in Ghana could attend, excel and complete school, the disparities among the females were wider than the disparities among the males. This result has serious implication for girls attending and completing school in Ghana since males are the bread winners of households in Ghana. However, because of government and donor funding at the basic level this is not likely to be a major problem. On the other hand, this can have serious implications for girls acquiring tertiary education in Ghana.

\subsection{Test of Hypothesis}

The chi-square test of independence revealed that $\mathrm{X}^{2}(1$, $\mathrm{N}=200)=18.714, \mathrm{p}=.000$.This means a chi-square with one (1) degree of freedom is equal to 18.714 , with $p$-value of $=.000$ from a sampled population of two hundred (200) respondents. A Chi-square Pearson value of 18.714 at 1 degree of freedom at a significant value $(\propto)$ of .000 . Table 2 shows the chi-square analysis of the study.

Table 2. Chi-Square Test of Independence

\begin{tabular}{|c|c|c|c|c|c|}
\hline & Value & df & Asymp. Sig. (2-sided) & Exact Sig. (2-sided) & \\
\hline Pearson Chi-Square & $18.714^{\mathrm{a}}$ & 1 & .000 & .000 & .000 \\
\hline Continuity Correction $^{\mathrm{b}}$ & 17.353 & 1 & 1 & & .000 \\
\hline Likelihood Ratio & 19.409 & 1 & & & .000 \\
\hline Fisher's Exact Test & & & \\
\hline
\end{tabular}

a. 0 cells $(.0 \%)$ have expected count less than 5 . The minimum expected count is 26.50 .

Again, from the chi-square test of independence (Table 2) $\mathrm{X}^{2}{ }_{(2)}=18.714, p$-value is significant (two-tailed). Thus, with $1 d f$, the Pearson value associated with the computed chi-square value is .000 from a two tailed sampled test (2 $\times 2$ ). The significant value (alpha) of the chi-square test of.000 is less than 0.05 and this means that there is sufficient evidence to conclude that there were significant relationships between parents' educational status and 
parents' belief about whether girls can attend, excel and complete school. Since, the significant value of .000 is less $(<) 0.05$, we reject the null hypothesis. Therefore, the null hypothesis $\left(H_{0}\right)$ is rejected at the 0.05 level of significance. Thus, the alternate hypothesis $\left(H_{1}\right)$ is rather retained.

In sum, since $.000<0.05$, the null hypothesis is rejected and therefore we can safely conclude that the two values that is parents educational status and parents belief and confidence about whether girls can attend, excel, and complete school are significantly related or dependent. The significant value of .000 obtained from the chi square test (Table 2) also reveals that the response variables were very strong.

\subsection{Implication of Results}

In pure encapsulated terms, parents who attend school are more likely to have confidence and belief (positive belief bias) that girls can attend, excel and complete school than parents who do not attend school (negative belief bias). This goes to establish the fact that parents' educational status has influence on parents' belief, level of confidence and perception about girls' abilities, capabilities and success in formal education. This is because parents' educational status can determine the kind and type of social modelling, economic support and psychological ram inter alia that girls will and can receive from their homes [21]. Again, because the acquisition of formal education in the Northern region is very low [6], it can have the potential of affecting girls acquisition of formal education in Ghana.

Apart from the fact that the international community and governments have made significant contributions to accelerate access and enrolment in formal education, they have also been making gargantuan contributions to increase retention, transition rate and completion rate of girls. However, in doing this, critical attention is not placed on dealing with the educational status of parents. This represents a lack of appreciation of the complex nature of the problem or a sheer lack of a comprehensive approach at ensuring that girls are able to attend and to progress through the educational ladder.

Even though educating girls is a civil and a fundamental human right, it also helps to circumvent intricate economic conditions, reduce vulnerability and provide social mobility for girls and women. However, from the study, if we consider only parents educational status as a factor of change in parents perception about the ability of girls to attend and complete school then it is safe to stressed that the educational status of parents' can potentially define and delineate girls' quest to attend and complete or excel in school in Ghana. This is very critical if at all we want to make good progress in increasing girls' enrolment in Ghana. According to Amenyah [1] girls enrolment in Ghana has declined significantly from 0.97 of General Performance Index (GPI) at the primary school level to below 0.6 of GPI at the tertiary level.

\section{Conclusion}

Globally, even though it has been extensively argued that girls have the ability and capacity to excel or complete school, there are some people who do not share this view. The significance of this study is potted within the fact that even in the wake of mounting evidence of the contribution of educated women and distinguished women in government and other high profile positions, there are still some parents who strongly hold the view that girls cannot attend, excel and complete school. The trajectory of this view is hauled on the educational status, religious, culture, life experience, level of exposure, illiteracy and personal belief systems of parents particularly of parents who have never attended school before.

Efforts to address the problem of school attendance, transition and completion of girls must be a holistic approach targeted at incorporating all aspects and factors that affect girls' school completion. Of particular importance but yet often ignored is the educational status of parents.

Albeit, the number of people (26.5 percent) who had belief that girls cannot attend, excel and complete school is far lower than the people who held a contrary view (73.5 percent) the magnitude and trend is alarming and is likely to adversely affect current efforts made in the area of enrolment, retention, transition and completion of girls in school in the Northern Region of Ghana.

\section{References}

[1] Amenyah, A. A., (2012). Violence and Abuse on Girls Education in Ghana. Ghana National Education Campaign Coalition. Ghanaian Chronicle.

[2] Bowling, A., (2002). Research methods in health. Buckingham, UK and Philadelphia, PA: Open University Press.

[3] Creswell, W. J., (2009). Research Design. Qualitative, Quantitative, and Mixed Methods Approaches SAGE Publications. Inc 2455 Teller Road Thousand Oaks, California 91320.

[4] Dijksterhuis, A. (2004). Think different: The merits of unconscious thought in preference development and decision making. Journal of Personality and Social Psychology, 87, 586598.

[5] Dijksterhuis, A. and van Olden, Z. (2006). On the benefits of thinking unconsciously: Unconscious thought increases postchoice satisfaction. Journal of Experimental Social Psychology, 42, 627-631

[6] Ghana Statistical Service, (2010). 2010 population and housing census; Northern Region: Analysis of district data and implications for planning. Accra: 5.

[7] Mack, N., Woodsong, C., Macqueen, KM., Guest, G., \& Namey, E., (2005). Qualitative Research Methods: A Data Collector's Field Guide. Research Triangle Park, NC: Family Health International.

[8] Maxwell, J. (2005), Research Design. An Interactive Approach Structured and unstructured Approaches, Applied Social Research Methods Series Volume 41 Approaches Sage Publications.

[9] McWilliamH, O.A., \& Kwamena-Poh, M.A. (1975). The Development of Education in Ghana. London: Longman.

[10] Meltzoff, A. N. (2002). Imitation as a mechanism of social cognition: Origins of empathy, theory of mind, and the representation of action. In U. Goswami (Ed.), Handbook of childhood cognitive development (pp. 6-25). Oxford: Blackwell Publishers.

[11] Moore, David S. and George P. McCabe (2006), Introduction to the Practice of Statistics, fifth edition, Freeman, p. 219.

[12] Opoku, J. Y., (2006). Tutorials in Inferential Social Statistics. Ghana Universities Press.

[13] Raven, B.H. (2008). The Bases of Power and the Power/Interaction Model of Interpersonal Influence, Analyses of Social Issues and Public Policy, 8, 1, 1-22.

[14] Silverman, D., (2006). Interpreting Qualitative Data: Methods for Analyzing Talk, Text and Interaction. London: Sage Publications Ltd.

[15] Stake, RE., (1995). The Art of Case Study Research. Thousand Oaks, CA: Sage Publications Inc. Statistics. 
[16] Tsiboe, I.A., (2004). A Look at Urban Waste Disposal Problem in Accra. Roskildem University. Unpublished.

[17] UNICEF (2007). Achieving Universal Primary Education in Ghana by 2015: A Reality or A Dream? Division of Policy and Planning. UNICEF 3 UN Plaza, NY, NY 10017.

[18] UNICEF, (2004). The State of the World's Children 2004 UNICEF, UNICEF House, 3 UN Plaza, New York NY 10017, USA.

[19] Walliman, N. (2006). Social research methods. London: SAGE publications.

[20] Wedam, E., Debrah, I. A., Atanga, R. A., (2014). Fighting Extreme Poverty In Ghana; A Stakeholders Analysis Of The
"Leap" Cash Transfer Programme. International Journal of Current Research. Vol. 6, Issue, 01, pp.4806-4814.

[21] Wedam. E., Debrah, I. A., Quansah. J., Y., D., (2014) Convoluted Path, Invisible Force and Girls' Education in Ghana. Education Journal. Education Journal, Vol. 3, No. 3, 2014, pp. 159-169.

[22] World Bank, (1996). The relevance of standard estimates of rates of return to "schooling" for education policy: A critical assessment. Journal of Development economics, 51(2), 267-290.

[23] Yin, R. K., (1994). Case Study Research Design and Methods: Applied Social Research and Methods Series. Second edn. Thousand Oaks, CA: Sage Publications Inc. 